DE

M E D I C I N A

T R O P I C A L

$\mathrm{DE}$

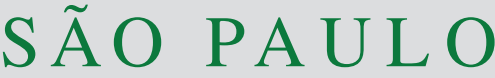

JOURNAL OF THE SÃO PAULO INSTITUTE OF TROPICAL MEDICINE

'Sociedad de Lucha Contra el Cáncer, Guayaquil, Ecuador

2Universidad Católica de Santiago de Guayaquil, Facultad de Medicina, Guayaquil, Ecuador

${ }^{3}$ Centro Dertamológico Ollague, Unidad Dermatológica Ollague, Guayaquil, Ecuador

${ }^{4}$ Universidad de Especialidades Espíritu Santo, Samborondón, Ecuador

Correspondence to: Juan Carlos Ruiz Cabezas

Sociedad de Lucha Contra el Cáncer Avenida Pedro Menéndez Gilbert y Atahualpa Chávez, 5225-3623, Provincia del Guayas, Guayaquil, Ecuador Tel: +59 34 371-8700 ext 2147, +5934 371-8300 ext 2143

E-mail: jruiz@solca.med.ec jcruizc@ hotmail.com

Received: 15 January 2019

Accepted: 16 July 2019

\section{Frequency and distribution of HPV genotypes in 800 genital samples of Ecuadorian men and women from the city of Guayaquil}

\author{
Gustavo David García-Muentes ${ }^{1,2}$, Marcia Adelaida Mendoza-García ${ }^{1}$, \\ Ramiro Israel Burgos-Galárraga', Kleber Ollague ${ }^{3}$, Cynthia Vargas-Wachter², \\ Juan Carlos Ruiz-Cabezas ${ }^{11,4}$
}

\section{ABSTRACT}

Even though there are data published on HPV epidemiology in Ecuador, the distribution of genotypes in Guayaquil, the largest city in the country, has not been previously determined in a study including including both, men and women. The present study aimed to determine the distribution of $37 \mathrm{HPV}$ genotypes in genital samples from Ecuadorian men and women living in the city of Guayaquil. Genital samples included in daily diagnostic routine were analyzed by the 37 HPV GenoArray Diagnostic Kit (Hybribio ${ }^{\circledR}$ Ltd., Sheung Wan, Hong Kong). The relative frequency of detectable genotypes was determined. HPV relative frequency according to sample characteristics, including sex and age groups, was compared using $\chi^{2}$ test. From the 800 samples (400 men and 400 women), 411 (51.38\%) were positive for HPV DNA. The obtained frequency was higher among samples from men (253/400 or 63.25\%) in comparison to samples from women $(158 / 400$ or $39.50 \%)$, with a p value $<0.05$. Samples from men showed a higher frequency of HPV genotypes 6,16,18 and 11, while among samples from women genotypes 39, 16, 6 and 58 were the most frequent. Considering male and female samples together, genotypes $6,16,39$ and 11 presented the highest frequencies. HPV DNA was detected in half of the studied samples, with a higher frequency among samples from men. Genotype 39 was the most frequent among women, and ranked third when samples from men and women are analyzed together.

KEYWORDS: HPV. Ecuador. Males and females. HPV genotypes

\section{INTRODUCTION}

Human Papillomavirus (HPV) genital infection, constitutes the most common sexually transmitted disease worldwide ${ }^{1}$. HPV is considered a highly contagious pathogen, transmitted by sexual contact, by contact with the skin or through inanimate objects ${ }^{2-6}$. According to the International Agency for Research in Cancer (IARC) and the World Health Organization (WHO), 12 HPV genotypes, namely $16,18,31,33,35,39,4551,52,56,58$ and 59, are considered high risk genoypes and belong to the group I of human biologic carcinogens. HPV 68 is classified as probably carcinogenic and genotypes $26,30,34,53,66,67,69,70,73,82$ and 85 are classified as possibly carcinogenic; these genotypes correspond to groups $2 \mathrm{~A}$ and $2 \mathrm{~B}$, respectively ${ }^{7,8}$. In previous studies on HPV epidemiology in Ecuador, many authors have identified a number of genotypes that were not HPV16 and HPV189-13.

The bivalent vaccine (HPV genotypes 16 and 18), which offers cross protection for some HPV genotypes of the same group as HPV16 (HPV31, HPV33, HPV35, 
HPV52, HPV58) and HPV18 (HPV39, HPV45, HPV59, HPV68), is funded by the government ${ }^{14-16}$. As the frequency of genotypes other than HPV16 and 18 is still not clear in Ecuador, the present study aimed to determine the relative frequency and distribution of HPV genotypes in 800 genital samples (400 obtained from men and 400 obtained from women), included in the daily diagnostic routine of the Instituto Oncológico Nacional de la Sociedad de Lucha Contra el Cáncer (ION SOLCA Matriz), in Guayaquil, Ecuador, which is responsible for the care of $50 \%$ to $70 \%$ of all cancers, in the country. The data obtained will provide guidance for prevention strategies, mainly of vaccination.

\section{MATERIALS AND METHODS}

\section{Clinical samples}

From January to December 2018 a cross sectional study was carried out in the Instituto Oncologico Nacional de la Sociedad de Lucha Contra el Cancer, in Guayaquil, Ecuador. During this period, a total of 800 genital brushings were obtained according to medical indication, from 400 men and 400 women aged 10-70 years old. Samples were consecutively enrolled in the study. Genital samples were collected by using the Hybribio ${ }^{\circledR}$ PCR Cell Collection Media at the outpatient service SOLCA, from January 2015 until December 2018. The collected samples were finally processed at SOLCA's Molecular Biology Laboratory, which is a reference laboratory in the city.

\section{DNA extraction}

DNA extraction was performed following the methodology recommended by the manufacturer.

\section{HPV genotyping}

HPV genotypes were identified using the 37 HPV GenoArray Diagnostic Kit (Hybribio ${ }^{\circledR}$ Diagnostics Ltd., Sheung Wan, Hong Kong) that identify the following 37 HPV genotypes: 16, 18, 31, 33, 35, 39, 45, 51, 52, 53, $56,58,59,66,68,26,34,40,54,55,57,61,67,69,70$, $71,72,73,82,83,84,6,11,42,43,44$ and 81 (CP8304) Following the protocol provided by the manufacturer, a conventional PCR using the PGMY set of primers was performed (Applied Biosystems ${ }^{\circledast} /$ Gene Amp ${ }^{\circledR} 9700$ thermal cycler). Immediately after amplification, the PCR product was denatured and hybridized through specific probes for $20 \mathrm{~min}$. Additional steps included an initial washing, aggregation of the conjugate, blocking of the hybridization, secondary washing procedures and the addition of the substrate. This last step triggers the appearance of a specific spot thanks to a color reaction that occurs in the presence of the corresponding HPV genotype.

The quality and the sufficiency of DNA samples for the PCR assays were evaluated by amplifying an internal control, that was included in the PCR mix. The absence of the internal control amplification constituted the samples exclusion criterium, even though the internal control of the dot blot had worked. This control was present in all the routines.

\section{Data analysis}

Results were considered positive if specific dot blots for any investigated HPV genotype and the internal control were present. The frequency and distribution of HPV genotypes was determined. HPV frequency according to sample characteristics (sex and age groups), was compared using $\chi^{2}$ test. There was no need to obtain the informed consent from participants as the data were retrieved from daily HPV genotyping routines. This study was not evaluated by ethics committees due to the hospital's internal policies.

\section{RESULTS}

From the total of 800 samples (400 from men and 400 from women), 411 were positive for HPV with an overall frequency of $51.38 \%$. The frequency for men samples $(253 / 400$ or $63.25 \%)$ was higher than that of women samples $(158 / 400$ or $39.50 \%)$, with a $p$ value $<0.05$. Comparing other characteristics, such as the detection of one or multiple HPV genotypes according to sex, or the frequency of HPV genotypes in different age groups, was not statistically significant with p values $>0.05$ (Table 1).

The most common viral genotype including both, men and women samples, was HPV 6, with 110 cases (relative frequency of 26.76\%), followed by HPV 16, with 67 cases (relative frequency of $16.30 \%$ ), HPV 39 with 43 cases (relative frequency of $10.46 \%$ ) and HPV 11 with 35 cases (relative frequency of 8.52\%). HPV 18 and HPV 58 were the following genotypes with 33 and 31 cases, respectively. Genotypes detected in women samples were: HPV 39 (17.09\%), HPV 16 (13.92\%), HPV 6 (13.29\%) and HPV 58 $(10.76 \%)$. Genotypes detected in men samples were: HPV 6 (35.18\%), HPV 16 (17.39\%), HPV 18 (10.67\%) and HPV 11 (10.28\%) (Figure 1). Overall, genotype 66, ranked seventh in frequency. Among female samples, this genotype exhibited a slightly higher frequency $(8.86 \%$ vs $5.93 \%)$ (Figure 1). From the 411 positive samples, in 168 multiple genotypes were detected: 93 had two genotypes, 39 had three genotypes and 36 had more than three genotypes. 
Table 1 - Frequency of HPV-positive or -negative samples according to sex, age group and presence of one HPV genotype or multiple genotypes.

\begin{tabular}{cccc}
\hline Variables & HPV + & HPV - & $\begin{array}{c}\text { p value } \\
\chi^{2} \text { test }\end{array}$ \\
\hline Sex & & & \\
Men & 253 & 147 & $<0.05^{*}$ \\
Women & 158 & 242 & \\
Age (years) & & & \\
$18-29$ & 144 & 120 & $>0.05$ \\
$30-39$ & 131 & 153 & \\
$40-49$ & 83 & 73 & \\
$50-59$ & 34 & 34 & \\
$60-70$ & 19 & 9 & \\
\hline Variables & One & Multiple & \\
& genotype & genotypes & $\chi^{2}$ test \\
\hline Sex & & & \\
Men & 157 & 96 & $>0.05$ \\
Women & 86 & 72 & \\
\hline
\end{tabular}

*Statistically significant

\section{CONCLUSION}

Human papillomavirus infection is one of the most prevalent viral sexually transmitted disease ${ }^{17}$. Approximately 291 million women are harboring HPV viruses at any time in life, with $23 \%$ of these infections related to HPV 16 and $8.5 \%$ to HPV $18^{18}$. The adjusted global prevalence has been reported as $10.41 \%$, with regional differences in the frequency of carcinogenic HPV infections ${ }^{1}$. In the case of heterosexually identified men, an overall prevalence of $50.5 \%$ was reported in the Study on Human Papillomavirus Infection in Men, that included participants from Brazil, Mexico and the United States ${ }^{19}$. Worldwide, 570.000 cancer cases per year in women and 60.000 cancer cases in men are attributable to HPV, representing $8.6 \%$ and $0.8 \%$ of all cancer cases. In the particular case of cervical cancer, infection rates standardized according to age that are over 30 per 100.000 are reported mainly in sub-Saharan Africa and some places in Latin America and Oceania ${ }^{20}$.

To our knowledge, HPV has not been studied in both men and women in the city of Guayaquil, Ecuador. Most of the samples were sent to the laboratory with little or no information on the participants' clinical conditions, previous diagnosis or treatment, besides gender and age. This lack of information was the main limitation of the study. The HPV frequency found in women samples $(39.50 \%)$ and reported here were similar to the one from a previous observational study, using similar methodology but with a larger sample size of 1,581 Ecuadorian women (43.58\%). We noticed, however, that some HPV genotypes associated

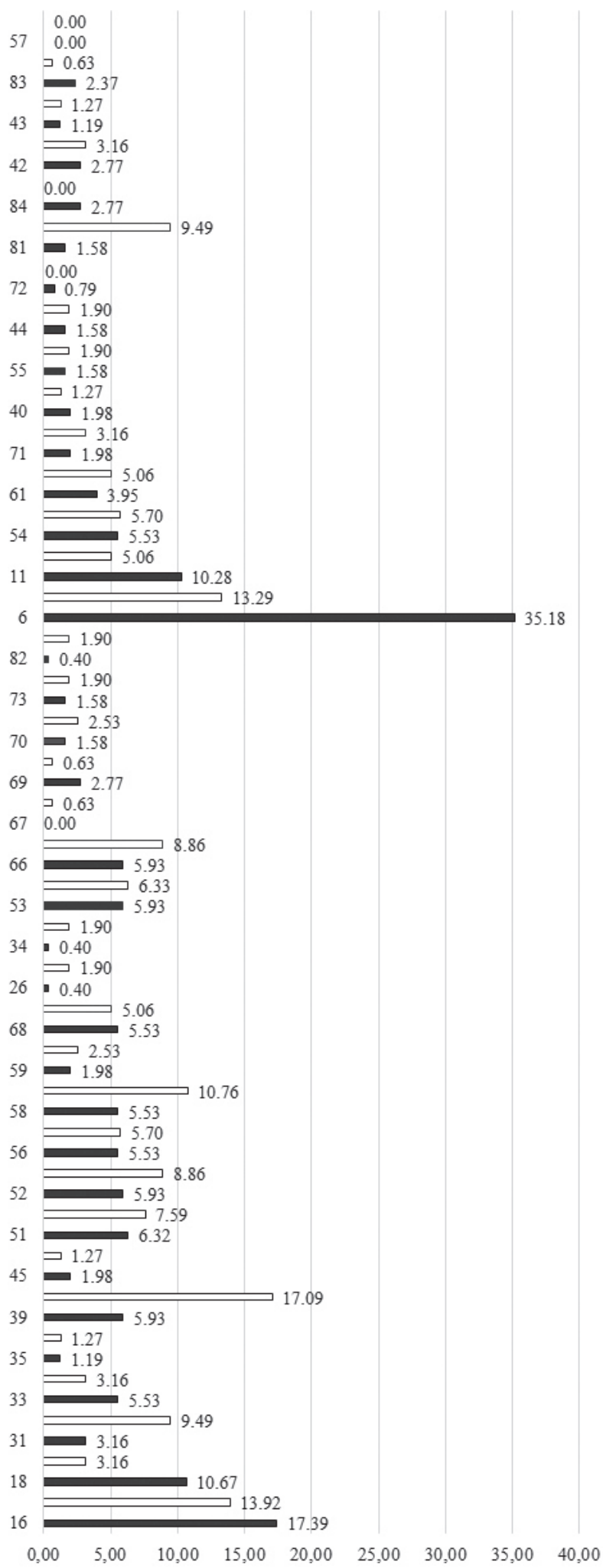

Figure 1 - Frequency of different human papillomavirus genotypes in men (depicted in black) and in women (depicted in white). 
with cancer, including HPV 39 and HPV 58, appeared to be more frequent according to the locality ${ }^{21}$. A Peruvian study has also indicated an analogous frequency of HPV infection (43.4\%), in a group of female college students ${ }^{22}$. On the contrary, a Colombian study reported a slightly higher frequency of HPV infection in female adolescents $(48.97 \%)^{23}$. In the case of men, the frequency reported in this study $(63.25 \%)$ was higher than the one reported for heterosexual men $(50 \%)^{24}$. Furthermore, we observed that male samples showed a higher proportion of infection by HPV genotypes covered by currently used vaccines. This finding supports the need of to include men in vaccination strategies. As mentioned by other authors, only bivalent and tetravalent vaccines have been available for vaccination in Ecuador $^{25-27}$. Due to the circulation of genotypes different from the ones covered by the available vaccines, a broader immunization strategy should be considered.

\section{CONFLICT OF INTERESTS}

There are no potential conflict of interests.

\section{ACKNOWLEDGEMENTS}

We acknowledge our technical personnel at the Molecular Biology Department.

\section{AUTHORS' CONTRIBUTIONS}

GDG participated in the conception, design, analysis and interpretation and in drafting the article. MAM collaborate with data collection analysis and interpretation. RB was involved in analysis, interpretation, and critical revision of the article. KO was responsible for critical revision of the article and data collection. CV collaborate with data collection, analysis and critical revision of the article. RCJC contribute with conception, interpretation and critical revision of the article.

\section{REFERENCES}

1. Nyengidiki TK, Bassey G, Durugbo I. Cervical cancer, a sequela of a sexually transmitted infection: the human papillomavirus infection. In: Kutlubay Z, Serdaroglu S, editors. Fundamentals of sexually transmitted infections. Zagreb: InTechOpen; 2017. [cited 2019 Jul 17]. Available from: https://www.intechopen. com/books/fundamentals-of-sexually-transmitted-infections/ cervical-cancer-a-sequela-of-a-sexually-transmitted-infectionthe-human-papillomavirus-infection

2. Gupta S, Palmer C, Bik EM, Cardenas JP, Nuñez H, Kraal L, et al. Self-sampling for human papillomavirus testing: increased cervical cancer screening participation and incorporation in international screening programs. Front Public Health. 2018;6:77.

3. Koutsky L. Epidemiology of genital human papillomavirus infection. Am J Med. 1997;102:3-8.

4. Gavillon N, Vervaet H, Derniaux E, Terrosi P, Graesslin O, Quereux C. Papillomavirus humain (HPV) : comment ai-je attrapé ça ? Gynecol Obstet Fertil. 2010;38:199-204.

5. Partridge JM, Hughes JP, Feng Q, Winer RL, Weaver BA, Xi LF, et al. Genital human papillomavirus infection in men: incidence and risk factors in a cohort of university students. J Infect Dis. 2007;196:1128-36.

6. Winer RL, Lee SK, Hughes JP, Adam DE, Kiviat NB, Koutsky LA. Genital human papillomavirus infection: incidence and risk factors in a cohort of female university students. Am J Epidemiol. 2003;157:218-26.

7. Annunziata C, Stellato G, Greggi S, Sanna V, Curcio MP, Losito S, et al. Prevalence of "unclassified" HPV genotypes among women with abnormal cytology. Infect Agent Cancer. 2018;13:26.

8. López-Díez E, Pérez S, Iñarrea A. Diagnosis and prevalence of high-risk human papillomavirus infection in heterosexual men. In: Rajkumar R, editor. Human papillomavirus: research in a global perspective. Zagreb: InTechOpen; 2016. [cited 2019 Jul 17]. Available from: https://www.intechopen.com/books/ human-papillomavirus-research-in-a-global-perspective/ diagnosis-and-prevalence-of-high-risk-human-papillomavirusinfection-in-heterosexual-men

9. Paez C, Konno R, Yaegashi N, Matsunaga G, Araujo I, Corral F, et al. Prevalence of HPV DNA in cervical lesions in patients from Ecuador and Japan. Tohoku J Exp Med. 1996;180:261-72.

10. Tornesello ML, Buonaguro L, Izzo S, Lopez G, Vega X, Maldonado Reyes CF, et al. A pilot study on the distribution of human papillomavirus genotypes and HPV-16 variants in cervical neoplastic lesions from Ecuadorian women. J Med Virol. 2008;80:1959-65.

11. Brown CR, Leon ML, Muñoz K, Fagioni A, Amador LG, Frain B, et al. Human papillomavirus infection and its association with cervical dysplasia in Ecuadorian women attending a private cancer screening clinic. Braz J Med Biol Res. 2009;42:629-36.

12. González-Andrade F, Sánchez D. HPV genotyping in anogenital abnormal samples of Ecuadorian women. Cancer Biomark. 2009;5:225-32.

13. Mejía L, Muñoz D, Trueba G, Tinoco L, Zapata S. Prevalence of human papillomavirus types in cervical cancerous and precancerous lesions of Ecuadorian women. J Med Virol. 2016;88:144-52.

14. De la Hoz Restrepo F, Alvis Guzman N, De la Hoz Gomez A, Ruiz C. Policies and processes for human papillomavirus vaccination in Latin America and the Caribbean. Rev Panam Salud Publica. 2017;41:e124. 
15. Harper DM, DeMars LR. HPV vaccines: a review of the first decade. Gynecol Oncol. 2017;146:196-204.

16. Bissett SL, Draper E, Myers RE, Godi A, Beddows S. Crossneutralizing antibodies elicited by the Cervarix ${ }^{\circledR}$ human papillomavirus vaccine display a range of Alpha-9 inter-type specificities. Vaccine. 2014;32:1139-46.

17. Zacharis K, Messini CI, Anifandis G, Koukoulis G, Satra M, Daponte A. Human papilloma virus (HPV) and fertilization: a mini review. Medicina (Kaunas). 2018;54:50.

18. de Sanjosé S, Diaz M, Castellsagué X, Clifford G, Bruni L, Muñoz $\mathrm{N}$, et al. Worldwide prevalence and genotype distribution of cervical human papillomavirus DNA in women with normal cytology: a meta-analysis. Lancet Infect Dis. 2007;7:453-9.

19. Giuliano AR, Lazcano-Ponce E, Villa LL, Flores R, Salmeron $\mathrm{J}$, Lee JH, et al. The human papillomavirus infection in men study: human papillomavirus prevalence and type distribution among men residing in Brazil, Mexico, and the United States. Cancer Epidemiol Biomarkers Prev. 2008;17:2036-43.

20. de Martel C, Plummer M, Vignat J, Franceschi S. Worldwide burden of cancer attributable to HPV by site, country and HPV type. In J Cancer. 2017;141:664-70.

21. García Muentes GD, García Rodríguez LK, Burgos Galarraga RI, Almeida Carpio F, Ruiz Cabezas JC. Genotypes distribution of human papillomavirus in cervical samples of Ecuadorian women. Rev Bras Epidemiol. 2016;19:160-6.
22. Manrique-Hinojosa J, Núñez-Teran MC, Pretel-Ydrogo L, Sullcahuaman-Allende Y, Roa-Meggo Y, Juárez-Coello P, et al. Detección del virus del papiloma humano en muestras obtenidas mediante técnica de autotoma en un grupo de universitarias peruanas. Rev Peru Med Exp Salud Publica. 2018;35:642-6.

23. Del Río-Ospina L, Soto-De León SC, Camargo M, Sánchez R, Mancilla CL, Patarroyo ME, et al. The prevalence of highrisk HPV types and factors determining infection in female Colombian adolescents. PloS One. 2016;11:e0166502.

24. Galea JT, Monsour E, Nureña CR, Blas MM, Brown B. HPV vaccine knowledge and acceptability among Peruvian men who have sex with men and transgender women: a pilot, qualitative study. PloS One. 2017;12:e0172964.

25. Delgado Ramos GM, Cotter TG, Flor Ramos L, Torres Floril V, Ramos Martinez GA, Ruiz-Cabezas JC, et al. A pilot study on the identification of human papillomavirus genotypes in tongue cancer samples from a single institution in Ecuador. Braz J Med Biol Res. 2018;51:e7810.

26. Silva G, Altamirano F, Montenegro W, Silva R. Prevalence and molecular epidemiology of human papillomavirus in Ecuadorian women with cervical cytological abnormalities. J Data Mining Genomics Proteomics 2015;6:1000174.

27. Bychkovsky BL, Ferreyra ME, Strasser-Weippl K, Herold CI, Lima Lopes Jr G, Dizon DS, et al. Cervical cancer control in Latin America: a call to action. Cancer. 2016;122:502-14.

\section{Erratum}

Page 1, where it reads:

Gustavo David García Muentes, Marcia Adelaida Mendoza García, Ramiro Israel Burgos Galárraga, Kleber Ollague, Cynthia Vargas Wachter, Juan Carlos Ruiz Cabezas

\section{Should be read:}

Gustavo David García-Muentes, Marcia Adelaida Mendoza-García, Ramiro Israel Burgos-Galárraga, Kleber Ollague, Cynthia Vargas-Wachter, Juan Carlos Ruiz-Cabezas

Rev Inst Med Trop São Paulo. 2019;61:e41err

http://dx.doi.org/10.1590/s1678-9946201961041err 